\title{
Clinical Profile and Outcome of Acute Poisoning Cases in Children Living in a Rapidly Urbanizing Area
}

\author{
Md. Nurul Islam*1, Naimur Rahman Ringku², Saiful Islam³
}

\begin{abstract}
Introduction: Acute poisoning is a common childhood emergency in Bangladesh. In many cases history and clinical features fail to identify the offending agent. This study was done to identify the specific clinical findings related with the source of poisoning and assess the outcome. Materials and Methods: It was a prospective study done from January to June 2020, among 75 indoor children of Tangail District Hospital. A preformed structured questionnaire was filled up by data collected from direct interview with the parents or caregivers, hospital records, during clinical examination. Results: We found the mean age of the study population 5.5 1.5 years having male preponderance 1.6:1 in ratio. Kerosene $16(21.33 \%)$ and organophosphorus compound 15(20\%) were the most common etiological agents and accidental (85\%) was the most common mode of poisoning. Most of the cases were asymptomatic 25(33.3\%). We encountered only 5(6.6\%) death having 62(82.6\%) complete recovery. Conclusion: Acute poisoning still remains a major cause of child death in Bangladesh. History remains the main information for early diagnosis. We should take necessary steps to prevent exposure to poisonous material in children to reduce related burden of hospitalization, mortality and morbidity.
\end{abstract}

Keywords: Acute Poisoning, OPC, Kerosene, Children.

Number of Tables: 07; Number of References: 20; Number of Correspondence: 06.

*1. Corresponding Author: Dr. Md. Nurul Islam MBBS, BCS (Health), DCH, MCPS (Pediatrics) Senior Consultant Department of Pediatrics 250 Bedded General Hospital, Tangail. Email: nurulshamim6@gmail.com Phone: 01711323492

2. Dr. Naimur Rahman Ringku, MBBS Medical Officer Rajdhani Nursing Home, Tangail.

3. Dr. Md. Saiful Islam, MBBS, DCH, FCPS (Pediatrics) Assistant Register 250 Bedded General Hospital, Tangail.

Introduction:

Acute poisoning is a common emergency around the world ${ }^{1}$. Although childhood mortality from infectious disease have declined for the last few decades there is steady increased proportion of death resulting from non-communicable diseases like, drowning, poisoning, snake bite, electrocution, injury etc ${ }^{2}$. Reduction of illnesses and deaths from hazardous chemicals and pollution is one of the health related goals of $\mathrm{SDG}^{1}$. Exposure to poisonous substance is a huge healthcare load for any pediatric emergency and indoor facilities ${ }^{3,4}$. There is increasing trend of acute poisoning related hospital admission and death in Bangladesh due to rapid economic development and easy accessibility of agro-chemical and other harmful substances ${ }^{5,6}$. Commonly used substances for acute poisoning in our country are herbicides, insecticides, sedatives, food substances, kerosene, rat killer, toilet cleaner; spirit and wooden polish etc. ${ }^{7,8}$. Children are especially vulnerable to accidental than other modes of poisoning ${ }^{9,10}$. The mortality and morbidity depends upon some factors like age of the patient, type of poison, quantity of exposure, time elapsed before hospital admission ${ }^{11,12}$. But early detection \& effective management also plays key role. This study was done to report the ever changing substance, mode of poisoning and to identify clinical profile along with outcome of acute poisoning cases admitted in a district level hospital where rapidly urbanization is going on. Thus, we can identify any changing pattern of poisoning for future action plan to prevent such a dreadful and upcoming childhood health hazard.

\section{Materials and Methods:}

It was a prospective study done from January/2020 to June/2020, among 75 indoor patients at pediatrics department of 250 Bedded General Hospital, Tangail. A Printed structured questionnaire was prepared before study. This was a secondary level district hospital where most of the patients came from primary centers like Upazilla Health Complex (UHC) and Union Sub-centers. Any acute poisoning case below 12 years old admitted by the emergency medical officer (EMO) into the indoor patient department of pediatrics was included in our study. Those children who were more than 12 years of age, treated in outpatient department(OPD) or in emergency room for observation, deny hospitalization, brought death, chronic poisoning, deny to give informed written consent were excluded from this study. Data were collected from parents and caregivers directly by interviewing. Detailed history regarding age, sex, socio-economic condition, mode of poisoning, place of occurrence, residence, 
transportation, condition of the children at arrival, time elapsed before admission in hospital was recorded. Clinical examination data were collected from patient's admission file and history sheet filled up by the duty medical officer in the department or by emergency medical officer. Outcome profile was taken from the patient's register book. Data were then analyzed with the use of Statistical package of social science (SPSS) version-23. Informed written conscent or thumbprint was taken from each parent. Permission was also taken from hospital authority before study.

\section{Results:}

A total 75 patients were enrolled in this study, Age range during admission was 1.5 to $12 \mathrm{yrs}$, mean average $5.5 \pm 1.5$ years, Male, female ratio was 1.6:1.About $50 \%$ of the total patient came from rural area, $26 \%$ patient came from remote area, and rest of the patients came from urban area. Total 50 patient $(66.66 \%)$ came from poor family, about 15 patients $(20 \%)$ came from middle class family, and rest 10 patients (13.33\%) came from higher society. Among 75, most of the patient affected by kerosene poisoning $(21.33 \%)$ \&OPC poisoning $(20 \%)$ drug poisoning $16 \%$, unknown poisoning $14.66 \%$, chemical $10.66 \%$, household substances $6.66 \%$, sedatives $6.66 \%$, others $2.66 \%$. Children mostly take the poison accidentally $(85.33 \%)$. On the other hand mother and caregivers sometimes give the poisonous substances to children unmindfully. Sometimes children accidently take drugs which are usually used for adults, like sedatives \& anxiolytic drugs etc. Now a day's homicidal poisoning $(9.33 \%)$ is not rare. It mainly occurs in broken family, disharmony of the parents or by the enemies. Due to ignorance or illiteracy, most of the patients did not came to hospital timely. Only $53.33 \%$ patient came to the hospital within 6 hours of ingestion of poison. Gastric lavage performed only 21 patients because most of the patient came in hospital after 6 hours. Some of the patients affected by corrosive agents like kerosene or sprit, where gastric lavage was contraindicated. Ultimate result after admission of the patient was good. Only 5patients $(6.66 \%)$ expired, another 5 patients $(6.66 \%)$ became disable, 3 patients $(4 \%)$ referred to higher centre for better management and 62 patients $(82.66 \%)$ completely recovered. Disability occurs due to corrosive substances. Eye, face $\&$ oral cavity affected due to corrosive substances (acid or alkali etc).

Table-I, reveals that about $42.66 \%$ Children of study group were in between 0 to 5years of age and 64 patients $(85.33 \%)$ out of 75 were Accidental Poisoning.

Table-I: Age distribution and pattern of poisoning.

\begin{tabular}{lccccc}
\hline \multirow{2}{*}{ Age Distribution } & \multicolumn{3}{c}{ Pattern of Poisoning } & \multirow{2}{*}{ Total } & \multirow{2}{*}{ Percentage } \\
\cline { 2 - 4 } & Suicidal & Homicidal & Accidental & & \\
\hline 0-5 Years & 0 & 4 & 28 & 32 & $42.66 \%$ \\
6-10 Years & 0 & 2 & 21 & 23 & $30.66 \%$ \\
10-12 Years & 4 & 1 & 15 & 20 & $26.66 \%$ \\
Total & 4 & 7 & 64 & 75 & $100 \%$ \\
\hline
\end{tabular}

Table -II, shows that most of the children came from rural area, it was near about $83 \%(56.66 \%+26.66)$.
Table-II: Geographical distribution of residence of the patients.

\begin{tabular}{lcc}
\hline Area of residence & No of patient & Percentage (\%) \\
\hline Urban Area & 13 & $17.33 \%$ \\
Rural Area & 42 & $56.66 \%$ \\
Remote Area & 20 & $26.66 \%$ \\
\hline
\end{tabular}

Table-III, shows that about two third patient's came from poor family).

Table-III: Social economic condition of the parents.

\begin{tabular}{lcc}
\hline Statues & No of patient & Percentage (\%) \\
\hline Poor & 50 & $66.66 \%$ \\
Middle Class & 15 & $20 \%$ \\
Affluent society & 10 & $13.33 \%$ \\
\hline
\end{tabular}

Table-IV, reveals that more than $50 \%$ children $(41.33+12)$ came to hospital within 6 hours of poison ingestion/ inhalation.

Table-IV: Hospital arrival after ingestion/inhalation of poisons.

\begin{tabular}{lcc}
\hline Time & No of patients & Percentage (\%) \\
\hline 0 to 1 hour & 9 & $12 \%$ \\
1hour to 6 hours & 31 & $41.33 \%$ \\
7hour to 24 hours & 25 & $33.33 \%$ \\
$>24$ hours & 10 & $13.33 \%$ \\
\hline
\end{tabular}

Table V showing most of the cases (33.33\%) were asymptomatic.

Table-V: Clinical features of acute poisoning cases.

\begin{tabular}{lcc}
\hline Clinical features & Cases & Percentage (\%) \\
\hline Asymptomatic & 25 & $33.33 \%$ \\
Vomiting & 20 & $26.66 \%$ \\
Abdominal pain & 11 & $14.66 \%$ \\
Dyspnea & 8 & 10.66 \\
Excessive salivation & 7 & $9.33 \%$ \\
Altered sensorium & 5 & $6.66 \%$ \\
\hline
\end{tabular}

Table VI shows that kerosene Poisoning (21.33\%) was the top most cause of acute Poisoning in children.

Table-VI: Source of poisoning.

\begin{tabular}{lcc}
\hline Types of poison & No of patient & Percentage (\%) \\
\hline Kerosene Poisoning & 16 & $21.33 \%$ \\
OPC poisoning & 15 & $20 \%$ \\
Drug poisoning & 12 & $16 \%$ \\
Unknown poisoning & 11 & $14.66 \%$ \\
Chemical poisoning & 8 & $10.66 \%$ \\
Household substance & 5 & $6.66 \%$ \\
Sedatives & 5 & $6.66 \%$ \\
Others & 2 & $2.66 \%$ \\
\hline
\end{tabular}

Table -VII shows ultimate recovery was good, it was about $82.66 \%$. 
Table-VII: Outcome of the cases.

\begin{tabular}{lcc}
\hline Outcome & No of patients & Percentage (\%) \\
\hline Death & 5 & $6.66 \%$ \\
Disability & 5 & $6.66 \%$ \\
Referred & 3 & $4 \%$ \\
Compete Recovery & 62 & $82.66 \%$ \\
\hline
\end{tabular}

\section{Discussion:}

We observed in our study that age of the maximum children $(42.66 \%)$ who ingested poisons around 5 years. Under five Children mostly affected by accidental poisoning. And it is almost similar to another study that published from another journal of India ${ }^{7,8}$. Younger children were more commonly affected with household chemicals as compared to older children who affected mainly by drugs ${ }^{13}$. We observed that there is a significant association between the rural residents and intention of poisoning. It has also been shown in another study conducted in Bangladesh ${ }^{3}$. Our Current study reported that older children easily take medicines which are usually used for the adult like sedatives, anxiolytics and other narcotics. Youngest children take medicinal products accidentally ${ }^{13}$. In Developing country like Bangladesh have the higher risk for medicinal poisoning in children. Sometimes drug overdose become a risk factor for poisoning in case of children ${ }^{13}$. In rural area children usually take herbicides, insecticides and other household substance because it's easy availability within own residence ${ }^{9}$. Sometimes children become victims accidentally by inhalation of insecticides during spraying to the plants. In the Living room area of the house and in kitchen area household containers were the commonest location for the poison in children in developing country. In our study we observed that most of the children found kerosene oil as the most common poisoning and those poisoning occurred in kitchen area or living room ${ }^{11}$. We observed that the $41.33 \%$ children were brought to the secondary care hospital emergency unit within 3 to 4 hours of poison ingestion or inhalation ${ }^{14}$. It was very much similar time compared to the other study in the India, that reported $60 \%$ affected Children came to nearby facilities within 3-4 hours and $70 \%$ within 6 hours $^{7}$. Delayed presentation to the emergency unit following poisoning is associated with increased risk of complications ${ }^{15,16,17}$. Delayed clinical presentation was inversely proportional to the outcome. Delayed transportation of children after ingestion of poison was one of the important risk factor in acute poisoning in rural area. Ignorance, illiteracy, poverty, lack of transport facilities, superstitions have been reported as the reason of delayed presentation in our country which was similar to another study done in Bangladesh ${ }^{2,3}$. Different poisoning pattern observed in different countries and regions. It varies country to country, region to region and different parts of the same country ${ }^{18,19,20}$. In our study we found that medicine accounted for $16 \%$ of all acute poisoning in case of children, we observed a large contribution from medicinal products for acute poisoning in children ${ }^{13}$. During study period 4 patients died due to aspiration pneumonia/ chemical pneumonitis in case of kerosene poisoning, one patient died due to OPC poisoning where gastric lavage, atropine, antidote pralidoxime, IV fluid was given. Data derived from our present study reveals that $20 \%$ cases due to OPC admitted in hospital ${ }^{3}$. Current study revealed that only 3 patients transferred to the tertiary care hospital for the further management. Above all results of the study indicates that public awareness must be improved to reduce mortality and morbidity of under 12 year's children. Limitation of the use of insecticides and pesticides should be strictly maintained, easy accessibility of such products should be monitored. In Bangladesh mortality rate from poisoning cases was reported at $5.1 \%$, in our study mortality rate is $6.66 \%$ which is similar to another study was done in rural hospital in Bangladesh ${ }^{3}$. Slightly higher mortality rate in our secondary level district hospital may be due to lack of ICU support, delayed transportation, immediate hospitalization and some superstitions.

\section{Conclusion:}

Acute poisoning still remains a major cause of child death in Bangladesh. Kerosene, OPC and drugs remain the most common source and accidental as the most common mode of poisoning. History remains the main information for early diagnosis. We should take necessary steps to prevent exposure to poisonous material in children to reduce related burden of hospitalization, mortality and morbidity.

\section{Conflict of Interest: None.}

\section{Acknowledgments:}

Thanks to all patients and caregivers who gave their valuable time during interviewing. Special thanks to Superintendent of 250 Bedded General Hospital, Tangail, Dr. Md. Sadar Uddin and Head of the department, pediatrics of the hospital, Dr. Md. Abul Farez for their cordial support from the beginning to the end of this study. We are also grateful to our colleagues for their constructive thinking and co-operation about this study.

\section{References:}

1. Sustainable Development Goals report. 2018. New York, United Nations.

2. Chowdhuri FR, Rahman AU, Mohammad FR, Chwdhuri A, Hasan HA, Bakar MA. Acute poisoning in southern part of Bangladesh -the case is decreasing. Bangladesh Med Res council Bull. 2011;37(2):61-5.

https://doi.org/10.3329/bmrcb.v37i2.8436

PMid:21877607

3. Sarkar D, Shahiduzaman M, Hussain MI, Ahmed N, Mohammed N, Bashar A. Spectrum of acute pharmaceutical and chemical poisoning in Northern Bangladesh. Asia Pac J Ed Toxicol. 2013; 2(1):2-5, do:10, 22038/apjmt;2013.508 
4. Dewan G. analysis of recent situation of pesticide poisoning in Bangladesh; is there a proper estimate? Asia Pac J Med toxicol. 2014; 3(2):76-83.

5. S. Sahin, KB Carman, EC Dinleyici. Acute poisoning in children, data of paediatric emergency unit. Iran J Pediatric. 2011; 21:479-484.

6. M.S.Bari, Chakroborty SR, Slam MMJ, Quayyam JA, Hasan N, Chowdhuri FR. Four years study on acute poisoning case admitted into a tertiary Hospital in Bangladesh, emergence tred of poisoning in commuters. Asia Pac J Med Toxicol. 2014;3(4):152-6. doi:10.18203/apjmt.2014,3485.

7. Agarwal V, Gupta A. Accidental poisoning in children. Indian Padiatrr.1984;11(9):617-21.

8. Bunch NA, Ahmed K, Seth AS. Poisoning in children. Indian Padiatrics. 1991;28(5):521-4.

9. Ramam MH, Samad MA. An epidemiological study of Acute poisoning in a rural hospital of Bangladesh. JOPSOM. 2000;19(1):40-46.

10. Md Abid Hossain Mollah. Chapter 36: Accidents and Emergencies. In: Mollah AH M, Nahar N., Step on to paediatrics. Dhaka, Bangladesh:Syeda Amena Meher. May 2018.

11. P Ram, T Kanchan, B Unnikrishnan. Pattern of acute poisoning in children $<15$ years-A study from Bangalore, S. India. J Forensic Med. 2014;25:26-29.

https://doi.org/10.1016/j.jflm.2014.04.001

PMid:24931857

12. YR Lin, TK Wu, TA Liu, CC Chou, HP Wu. Poison exposure and outcome of children admitted to a pediatric emergency department. World J Pediatrics. 2011;7:143 -149 .

https://doi.org/10.1007/s12519-011-0267-7

PMid:21574031

13. GR Band, RW Woodward, M Ho. The growing impact of pediatric pharmaceutical poisoning. $\mathrm{J}$ Pediatrics. 2012; 160:265-270. https://doi.org/10.1016/j.jpeds.2011.07.042

PMid:21920539

14. A Ahmed, AN A Jamal, MI M Ibrahim, K Salamah, K A Yafei, SA Zaineh, et al. Posoning emergency visits among children; a 3 years retrospective study in Qatar. BMC Pediatr. 2015;15:104.

https://doi.org/10.1186/s12887-015-0423-7

PMid:26315670 PMCid:PMC4551530

15. JH Woo, E Ryoo. Poisoning in Korean children and adolescent. Pediatric Gastroenterol Hepatol Nutr. 2013;16:233-239.

https://doi.org/10.5223/pghn.2013.16.4.233

PMid:24511519 PMCid:PMC3915731

16. T Bacha, B Tilahun. A cross sectional study of children and acute poisoning; a 3 years retrospective analysis. World J emerg Med. 2015;6:265-269.

https://doi.org/10.5847/wjem.j.1920-8642.2015.04.003

PMid:26693260 PMCid:PMC4677068

17. G Agarwal, KS Bithu, R Agarwal. An epidemiological study of acute poisoning in children in a tertiary care hospital of western Rajasthan, India. Int $\mathbf{J}$ Contemp Pediatr. 2016;3:1249-1251.

https://doi.org/10.18203/2349-3291.ijcp20163653

18. R Fernando, DN Fernando. Children poisoning in Srilanka. Indian J Pediatr. 1997;64:457-466.

https://doi.org/10.1007/BF02737748

PMid:10771874

19. AMA Hazmi, AB Ped. Patterns of accidental poisoning in Jeddah, S. Arabia. Annals of Saudi Medicine. 1998;18(5):457-459.

https://doi.org/10.5144/0256-4947.1998.457

PMid:17344734

20. H Aldeen, M Khan, RA Madani. Accidental poisoning in children in Bahrain. Bahrain Med Bull. 1999;21(1):6-13. 